\title{
A CURADORIA DIGITAL COMO MEIO DE PRESERVACÃO E DIFUSÃO DA COLEÇÃO DE TESES E DISSERTAÇÖES DO INSTITUTO MILITAR DE ENGENHARIA
}

\begin{abstract}
Resumo: Este artigo tent o objetivo de propor a utilizaçẫo da curadoria digital como meio de difundir e preservar a coleção de teses e dissertaçðes do Instituto Miłitar de Engenharia. Insere-se no. contexto atual tendo en vista que se refere aos debates sobre a preservação da produçăo cientifica acadêmica na área de ciência e tecnologia e parte do pressuposto que nầo há futuro sem passado, ou seja, a preservaçăo, neste caso, digital faz,se necessária. Caracteriza a importância do acervo do lnstituto Militar de Engenharia - IME que foi a primeira escola de engenharia das Americas e terceira do mindo, assim como faz uma análise sobre alguns marcos teórico-conceituats. como repositórios institucionais, preservação digital c curadoria digital: Apresenta dados consolidados em relaçẫo ao acervo da Bibliotcca General Armando Ferreira Dubois e todas as publicaçôes. ali contidas. Por fim conclui que o Institusto Militar de Engenharia necessita preserval sua produçăo acadêmica através de um projeto de digitalização em curso para que assim este material seja disponibilizado no repositório institucional do Exército Brasileiro, a Biblioteca Digital do Exército - BDEx; aleançando assim a preservaçāo de seu acervo cjentifíco e seguindo as normas e padrōes nacionais e internacionais que garantem a acessibilidade, integridade, confîabilidade e a disseminaçâo da informação.
\end{abstract}

Palavras-chave: Curadoria digital. Preservaçăo Digital. Bịbliotecas universitárias: Produção científica. Ciência e Tecnologia.

\author{
Vanessa Ferreira Belchior \\ Mestre em l'reservaçäo de \\ Acervos de Ciência e \\ Tecnologia do Museu de \\ Astronomia e Ciênciás Afins - \\ MAST, Bibliotecária chefe do \\ Instituto Militar de Engenharia - \\ IME. nessabelchior@gmail.com
}

\footnotetext{
Adriana Cox Hollós

Doutơra em Ciênoia da Informaçà pelo Programa de Pós-graduaçãa do Instituto Brasileiro de Informação, Ciência e Tecnologia - IBIC T. Professora Pertnanente do Mestrado Profissional em Preservação de Acervos de Ciência e Tecnologìa do Museu de Astronomia e Ciências Afüns

- MAST. ahollos@gmail.com
}

\section{DIGITAL CURATORSHIP AS A WAY OF PRESERVATION AND ISSEMINATION OF THE COLLECTION OF THESES AND DISSERTATIONS OF THE MULITARY ENGINEERING INSTITUTE}

\begin{abstract}
This article has the objective of providing the use of digital curatorship as in means of disseminating and preserving the coltection of theses and dissertations of the Military Institute of Engenharia. Inserting no current context 1 intend to refer to the debates on the preservation of the academic scientific production in the area of science and technology and part of the prësupposition that it has not been in the future, in this case; preservation, in this case, digital face. if necessary. it characterizes the importance of the heritage of the Military Institute of Engenharia - IME, which was the first school of engineering in the Americas and the third world, as well as an analysis of some theoretical-municipal frameworks such as institutional repositories, digital preservation and digital curatorship. It presents consolidated data in relation to the acquis of the Armando Ferreira Dubois General Library and all the publications therein. Finally, it concluded that the Military Institute of Engenharia needs to preserve its academic production through a digitization project in progress so that this material is made avatiable not an institutional repository of the Brazilian Army, to the Digital Library of the Army - BDEx, reaching assim to the preservation of seu scientific heritage and following the standards and national and international standards that gutarantee accessibility, integrity, reliability and dissemination of information.
\end{abstract}

Palavras-chave: Dígital curator. Digital Preservation. University litbraries. Seientific production. Science and Technology, 


\section{INTRODUÇÃO}

Este artigo é resultado de uma dissertação de mestrado que trata sobre a utilização da curadoria digital como meio de preservar e disseminar a coleção de teses e dissertações do Instituto Militar de Engenharia (IME). O objetivo deste estudo foi demonstrar a importância deste acervo, tendo em vista que o IME foi a primeira escola de engenharia das Américas e a terceira do mundo.

A proposta de trabalho consistiu em se refletir sobre a importância da curadoria digital como meio de difusão e acesso à coleção, uma vez que já existe uma proposta de sua digitalização. Tal proposta, em verdade, corrobora com o objetivo do Estado-Maior do Exército Brasileiro, que disponibilizou, em 2018, um repositório digital nomeado de Bibliotecá Digital do Exército - BDEx, visando a otimização de recưrsos para viabilizar a difusão das produçōes bibliográficas do Exército Brasileiro.

O artigo encontra-se estruturado de forma a propor uma reflexão sobre a utilização da curadoria digital cọmo meio de difusão dos acervos de interesse para a história, a memória e as ciências, favorecendo assim a sua preservação e o seu conhecimento pela comunidade.

\section{MARCOS TEÓRICOS CONCEITUAIS}

Observou-se que, cada vez mais, as práticas de preservaçăo e curadoria digitais se aproximam, à medida que ocotre o crescimento dọ volume de informação, a fragilidade e a obsolescência dos formatos digitais e seưs suportes, bem como a forma como se busca enfrentar o problema da conservação desses materiais, aliados à necessidade de acesso e difusão dos acervos, como destaca Hollós (2006, p. 37). Essa abordagern se justifica pelo fato que preservação e curadoria digitais são conceitos complementares e que para que possam ser operados, precisam ser mais bem compreendidos pela sociedade e peios pesquisadores.

No intuito de dar a conhecer o contexto no qual os conceitos selecionados operam, considerou-se importante apresentar, a seguir, um breve histórico sobre a trajetória de cada um, iniciando pelos repositórios digitais, sendo que, posteriormente, abordou-se a preservação digital e de forma mais recente a curadoria digital.

I Disponịel em: http://www.bdex.eb,mil.br/jspuil. Acesso em: 10 maio 2019. 


\subsection{REPOSITÓRIOS INSTITUCIONAIS}

Com o desenvolvimento das tecrologias de informação e comunicação, que provocaram maior rapidez e transparềncia nos processos da comunicação científica, as instituições de ensino e pesquisa têm buscado opçōes para a confiabilidade das informações ali produzidas, aprimorando o ciclo de produção da informação. Nesse sentido, a implantação de repositórios institucionais é uma das maneiras que as instituições acadêmicas de pesquisa e tecnologia têm buscado para ampliar o acesso e a difusāo de sua produção científica.

Acrescenta-se que "a internet criou a oportunidade de disponibilizar literatura cinzenta ao público sem os custos da publicação tradicional", e que neșta mudança vislumbra-se a oportunidade de geração de novos produtos de informação (SONDERGAARD, 2003, p. 297).

Ferreira $(2008$, p. 125) explicitou que "[...] o conceito de repositório digital sofre constante evoluçâa", podendo abrigar a produção intelectual de uma instituição. Esta autora ressalta ainda que os repositórios atuam como veículos de difusão informal e ägil da produção científica.

Na pesquisa realizada, identificou-se que os repositórios institucionais vềm sendo estudados tanto em âmbito nacional qưanto internacional, o que possivelmente contribuiu para gerar uma divẹrsidade de definições para o termo.

No dizer de Lynch (2003), os repositórios institucionais surgiram como uma nova estratégia que permitiu as universidades assumirem o papel de editoras modernizando os processsos da comunicação científica da produção acadêmica em conteúdo digital. O referido autor define repositórios institucionais como um "conjunto de serviços que uma universidade oferece aos membros de sua comunidade para a gestão e disseminação de materiais digitais criados pela instituição e por membros da sua comunidade":

Para Ferreira (2008, p. 133) "os repositórios também estão sendo empregados como recursos fundamentais para o compartilhamento, o aprendizado e a reutilização de materiais de aprendizado e ensino [...]".

Diante destas definições, o repositório institucional pode ser entendido como uma ferramenta, possibilitada pelo desenvolvimento das tecnologias digitais de comunicação, a qual instituições de ensino e pesquisa, como as universidades, podem utilizar para reunir, organizar e divulgar a produção científica de sèu corpo docente e discente na web, além da preservação desse material, desde que a instituição tenha uma política institucioṇal de preservação digital.

Implantar um repositório, além de preservar e disponibilizar a informação científica em acesso aberto à comunidade acadêmica e à sociedade, "[...] incorpora a facilidade de 
comunicação, da colaboração e de outras formas de interaçẩo dinâmica entre usuários de um vasto universo" (MARCONDES; SAYÃO, 2009, p. 26).

Nesta pesquisa, considerando o acervo de teses e dissertaçōes do IME, os termos "mudança de estado" e "fazer uso de" permitem compreender o sentido do conceito de "reuso" aqui utilizado. A revisão de literatura, em especial na área da Ciência da Informação, possibilitou identificar e selecionar artigos e dissertaçóes que utilizavam as seguintes abordagens para o termo: reuso da informação, reuso de documentos, reuso de metadados e reuso de software.

Marcondes e Sayão (2009), ressaltam em seu trabalho a dimensão alcançada; em nível mundial, da iniciativa dos arquivos abertos e as possibilidades que eles oferecem para o reuso de metadados. Em outras palavras, a definição de reuso da infợmação considera as possibilidades que oferece aos docentes e discentes do IME, como apoio ao ensino na pósgraduação, utilizando a produção intelectual armäzenada na biblioteca do instituto.

Em adição ao que fọi exposto, como estamos apresentando ự ambiente acadêmico, em que o repositório é utilizado como fonte de reuso da produçăo acadềmica, torna-se necessário. abordar a Biblioteca Digital de Teses e Dissertaçồes (BDTD) ${ }^{2}$ criada pelo Instituto Brasileiro de Informaçăo em Ciência e Tecnologia (IBICT).

Ao acessar a página inicial da BDTD é possivel verificar a quantidade atual de instituiçōes cadastradas, assim como o número atual de teses e dissertações disponiveis em formato digital, conforme a Figura 1.

2 Sobre a BDTD, o fBICT alïma que A Biblioteca Digital Brasileira de Teses e Dissertaçoes (BDTD) integra e disșemina, em um só portal de busca, os textos contplefos das teses e dissertaçðes defendidăs nas instituições brasileiras de enisino e pesquisa. $\mathrm{O}$ acesso a essa produçăo cientifica é livre de quaisquer custôs. A BD TD contribui para o anmento de conleửos de teses e dissertaçôes brasileiras na ịnternet, o que s̈ignifica a maior visibilidade da produçâo científictca nacional e a difusăo de

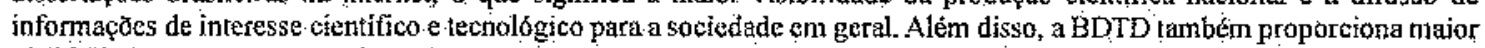
visibilidade e govenariça do inveștimento rẹalizado en programas de pós-graduação. 


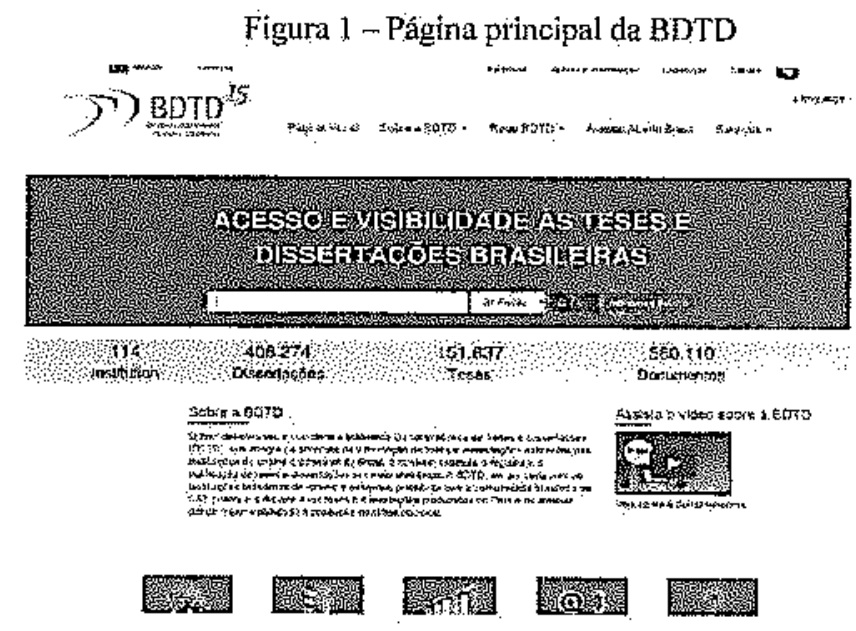

Fonte: http://bdtd.ibict.br/vufind/ Acesso em: 19 fev. 2019

Como percebemos, a página prinçipal da BDTD apresenta informaçổes referentes à interface de busca da biblioteca, aos indicadores e à forma de gerenciar os repositórios. $O$ repositório informa ainda que disponibiliza mais de 560 mil teșes e dissertações.

As instituiçōes de ensino superiơr necessitam inicialmente adotar o Padrão brasileiro de Metadados de Teses e Dissertações (MTD-BR) para aderir ao repositório. Tal padrão foi desenvolvido pelo IBICT con padrão compatível ao Dublin Core $^{3}$, ETD-MS ${ }^{4}$ da NDLTD ${ }^{5}$, assim como a implementação da camada protocolo OAl-PMH ${ }^{6}$ para exposição dos metadados referentes ảs teses e dissertações ali publicadas. O padrão MTD-BR é utilizado para descrever os metadados de teses e dissertações em formato digital para intercâmbio entre o sistema BDTD e outros.

Todavia, o Exército Brasileiro optou por não utilizar a BDTD para inserç̧ão da produçầo cientifica de pós-graduaçâo e criou seu próprio repositório institucional, visando ter sob seu controle e mediação as publicaçốes relacionadas às normas e padrões reșervados, assim como as publicações de interesse da sociedade, que ampliam o acesso à pesquisa.

3 Dublin Core - Escuema de mefadados que visa descrever objetos digitais, tais como, vídeos, sons, imagens, textos e sites na web.

4 ETD-MS - Padrão de Metadados para interoperabilidade ușados para escrever una Tesce ou Dịssertaçāo. eletrônica;

5 NDI.TD - Networked Digital Library of Theses and Dissertation (Biblioteca Digital em Rede de Teses e Dișsertaçōes).

6 OAI - PMH - Open Archives Initiative Protocol for Metadata Harvesting. Protocolo desenvolvido pela Open Archives initiative que define un mecanismo para coleta de registros de metadados em repositórios. 
Sobre a criação de repositórios institucionais, em uma palestra, Luis Fernando Sayão levantou uma questão importante': a criaçāo dos repositórios é crucial para a preservação e difusão, porém; como fazer para que eles continuem ativos e não se tornem repositórios "fantasmas"? A criação de um repositório inclui principalmente sua gestão e políticas voltadas para a sua manutenção. O mesmo autor enfatiza que "há um consenso claro entre as comunidades envolvidas de que a preservação digital antes de ser problema tecnológico é, sobretudo, um problema organizacional, político e de gestão" (SAYÃO, 2010, p. 73).

Como forma de mitigar esta questão, o Exército Brasileiro criou alguns mecanismos para a manutenção da BDEx como a criaçâa do Portfólio de Apoio à Gestão do Conhecimento para o Exército Brasileiro - PAGC, que se define como "uin conjunto de plataformas digitais que abriga as bases de dados referentes à gestão de informaçẩo no Exército Brasileiro- EB"s. Desta forma, conșegue viabilizar recursos e montar politicas futuras para a manutenção do repositório.

\subsection{PRESERVAÇÃO DIGITAL E CURADORIA DIGITAL.}

A preservação digital é uma disciplina que cada vez mais vem sendo associada aos arquivos, museus e bibliotecas e que ainda implica em muitos desafios tendo em vista que a produçã̉o de informaçã̉o em meio digital continua a crescer exponencialmente. Em outras. palavras, sobre este crescimento, Hollós (2006, p. 59) destacou que "Em 2010, o volume era de algo em torno de cinco exabytes de informação digital produzida, o que corresponderia aproximadamente a quase cinquenta exabytes; em 2015 , ou o equivalente a 500 mil bibliotecas do Congresso Americano, que é a maior do mundo."

Em 2003, a UNESCO lançou a "Carta sobre Preservação do Patrimônio Digital"10, a fim de conscientizar as nações sobre a importância da preservação dos acervos digitais, tendo em vista considerar que na maioria das instituições não havia a preocupação de que é possivel

7 Palèstra apresentada no I Seminário de Gestão de dados de pesquísa UNIFESP e UFABC em agosto de 2018.

8 Portaria $\mathrm{N}^{\mathrm{N}} 254$, de 27 de fevereiro de 2019.

9 UNEŞCO - A Organizaçẵo das Nạcões Unidas para a Educação, a Ciência e a Cultura - (acrônímo de United Nations Edtucational, Scientific and Cultural Organization) é unta agência especializada das Naçồ Unidas (ONU) com sede em Paris, fundada em 4 de novembro de 1946 com o objetivo de contribuir para a paz e șegurança no mundo mediante a educação, ciências naturais, ciências sociais/humanas e comunicações/informação.

10 Estabelecida pela $32^{n}$ Reunião da Conferênicia Geral da UNESCO, em 19 de agosto de 2003 , Paris - França. Disponivel em: <htip://unesdoc.unesco org/mages/0013/001311/131178s.pdts. Acesso em: 14 fev 2019. 
afetar significativamente o futuro da memória de inștituições, movimentos sociais, partidos políticos, associações de comunidades, entre outros.

A Carta sobre a Preșervação do Patrimônio Digital manifesta a necessidade de os Estados membros, estabelecerem políticas e ações para proteger o patrimônio digital.

Neste sentido, diante do crescimento da informação digital Höllós (2014, p. 57) afirma que "a que se reconhecer que a digitalização da sociedade se constitui como uma potência na criaçăo de um bem comum, de uma riqueza e sentido comuns, compartilhados em rede."

No entanto, apesar da intensa produção de documentos já nascidos em meio digital a humanidade corre o risco de passar por um processo de "amnésia digital", que tende a ameaçar "[...] os acervos culturais, as informações para os negóciọ, os documentos governamentais, os dispositivos legais e tudo o que a sociedade produz em formato digital [...]" (SAYÃO, 2016, p. 169). Na mesma linha, Hollós (2014, p. 25) alerta para a "amnésia digital" com impactos negativos para as gerações futuras, que não poderạo pesquisar e coṇecer a histórịa e desenvolver um sentido de pertencimento e cidadania.

No meio científico, o volume de informação que vem sendo produzido, armazenado e disponibilizado em meio digital também é crescente, sendo resultado de pesquisas e investimentos. Desta forma, a preservação digital de conteúdos cientificos deve ser vista como uma questão urgente, pois a perda das informações pode comprometer a pesquisa cientifica e ainda abrir uma lacuna histórica e cultural da herança e da memória da sociedade. Dentre as pesquisas voltadas para a área de preservação digital, identifica-se a curadoria digital como uma das temáticas mais abordadas; mediante o número crescente de informaçōes.

Preservaçấo digital é uma realidade, está em tudo o que fazemos e está intrínseca à sociedade. A preservação digital ế uma realidade que não pode ser ignorada pela sociedade e pelas instituições, principalmente as instituições de ensino e pesquisa, tendo em vista que se constituem em atividade crucial para o desenvolvimento das atividades, confiabilidade da pesquisa e de preservação da memória social. Por conseguinte, abordaremos adiante detalhes sobre a curadoria digital, discutindo seu conceito, diferenciando-o da preservação digital, além de abordar modelos de preservaçăo.

Ao longo dos anos, desenvolveram-se técnicas que focassem na preservação de tais objetos digitais com a preocupação de poder acessá-los em longo prazo. A palavra curạdoria pode ser definida no contexto da definição de coleção, já qque esta é um conjunto de objetos materiais ou imateriais reunidos por um indivíduo ou estabelecimento (DESVALLÉES; MAIRESSE, 2013). Sendo assim, a definição de curadoria é "o processo que integra todas as ações em torno da coleçẫo ou do objeto museológico: aquisição, pesquisa, conservação, 
documentaçã̃o, comunicação (exposição e educação)" (DESVALLÉES; MAIRESSE, 2013, p. 33).

Com relaçã̃o ao termo "curadoria digital" sua primeira utilização ocorreu no seminário "Digital Curation: digital archives, libraries and e-science seminar" patrocinado pela Digital Preservation Coalition e pelo British National Space Centre em Londres, em 11 de outubro de 2001 (BEAGRIE; 2006, p. 4).

Neste cenărio, surge no Reino Unido, em 2004, o Digital Curation Centre (DCC) ${ }^{11}$ representando um reflexo do pensamento de que o gerenciamento em longo prazo de objetos digitais é uma responsabilidade de todos dentro da cadeia de ușo da informação digital (RUSBRIDGE, C. et al., 2005). O autor entende que a curadoria digital é um contínuo de atividades de apoio para utilização atual e futura.

Abbott (2008) amplia um pouco mais a ideia de curadoria digital definindo-a como todas as atividades envolvidas na gestão de dados, desde o planejamento da sua criação quando os sistemas são projetados, passando pelas boas práticas na digitalização, na seleçã̃o dos formatos e na documentaçậo, e na garantia de estar disponível e adequado para ser descoberto e reusado no futuro.

O discernimento đo que serve ou não no mundo digital é de responsabilidade do curador. A curadoria digital é um filtro em meio ao crescimento de informações digitais e pode ser uma alternativa para organizações. A curadoria digital deve acontecer dentro da instituição, em conjunto com uma boa gestão documental e políticas de funcionamento dos Repositórios Digitais, contribuindo com as tecnologias que serão utilizadas. A questão do acesso à informaçăo de maneira fácil e em qualquer período é uma das grandes preocipações da curadoria digital.

Da mesma forma, Dutra e Macedo (2016) citam Abbott (2008), que afirma que a curadoria digital inclui o gerenciamento de uma vasta quantidade de datasets ${ }^{12}$ de uso diário, visando garantir que eles estejam visiveis e acessíveis, e que assim continuem. Para ela, a ideia de curadoria digital é aplicável a uma vasta gama de atividades piofissionais, do início ao fim do ciclo de vida dos objetos digitais, sendo passível de ser trabalhada por meio de:

I I Site oticial do Centro de Curadoria Digital (DCC); http://www.dcc.ac.uk/digital-curation/what-digital-curation.

12 Datasets - são o principal insumo dos processos de análise de dados. Eles sào representados por dados tabulares em formato de planilha onde as linhas sāo os registros dos acontecimentos e as colunas sấo as características desses acontecimentos. Fonte: hitps://www.aquare,fa/datasets-o-que-sao-e-como-utiliza-los/ Acesso em: 01 mạ. 2019 . 
digitalizadores (scamers), criadores de metadados, financiadores de projetos, legisladores, geștores de repositórios digitais, dentre outros.

Yakel (2007) declara que diversos conceitos estão relacionados às curadorias digitais, dentre os quaís podemos destacar:

a) Gerenciamento do ciclo de vida dos materiais desde a sua criação;

b) Interaçăo ativa ao Iongo do tempo entre os criadores de materiais e os potenciais curadores digitais;

c) Avaliação e seleção (appraisal);

d) Disponibilização de acesșo;

e) Garantia de preservação com ênfase na usabilịdade e acessibilidade doṣ objetos digitais.

Diante do fato de que alguns dadọ de pesquisa são únicos e não podem ser substituídos se forem destruidos ou perdidos, a questão cricial que se coloca é a segunte: será que os atuais [...] registros de pesquisa que estão sendo documentados de forma digital ou já são gerados em. fórmatos digitais estarão disponiveis para o acesso e para a reutilizaçấo em novas pesquisas. daqui a alguns anos? (SAYÃO; SALES, 2012, p. 179).

Dutra e Macedo (2016, p. 144) complementam os questionamentos citados acima pelos autores quando relatan ser neceșsário encontrar respostas para questões do tipo: "Quais são as implicações em longo prazo do crescimento da geração inintertupta e exponencial de novos dados?", "Onde estes dados serão armazenados?", e "Como eles serão processados, de maneira a poderem ser extraídos e recuperados?".

Em face aos questionamentos dos autores utilizados como fonte nesta revisão de literatura, Sayẫo e Sales (2012, p. 180), no intuito de pôr em prática soluçōes para o problema, observam, no âmbito de várias disciplinas, um esforço em torno do desenvolvimento de repositórios digitais orientados especialmente para uma gestão ativa de dados de pesquisa. $\dot{E}$ nesse ambiente que surge o conceito de curadoria digital de dados científicos, cujo principal desafio recai na necessidade de se preservar não somente o conjunto de dados, mas de preservar, sobretudo, a capacidade que ele possui de transmitir conhecimento para uso futuro das comunidades interessadas: Isto significa que os objetos digitais genuínos da pesquisa científica devem permitir que tuturos usuários reusem os dados dentro de novos contextos.

$O$ fato de a curadoria digital ser regularmente mencionada em conjunto com a preservação digital, o campo de pesquisa e prática profissional a partir do qual se originou (DALLAS, 2016) e muitos pesquisadores e profissionais se afiliarem quase indistintamente aos 
doị assuntos, traz à tona a questẫo da diferenciação entre curadorija digital e preservaçắo digital como campo de pesquisa e especialização profissional.

O conceito de curadoria digital evolui a cada dia, mas aparece em um cenário em que á obsolescência tecnológica se intensifica e tona-se necessário se preocupar cada vez mais com a fragilidade das rúdiäs e ambientes digitais e com as práticas de preservação digital. Por se tratar de um processo colaborativo, que envolve um conjunto de atores, fica ao curador a missão de liderar este processo, fazeñdo uma gestão atuarite e coordenando as açónes. Um dos principais desafios da curadoria digital está na necessidade de se preservar o conjunto de dados e, sobretudo, a capacídade que ele possuii de propagar conhecimento para uso futuro, segundo Sayão e Sales (2012).

Em resumo, evidencia-se que a curadoria digital abrange todo o ciclo de vida dos documentos digitais, o que demanda investimento de tempo e recursos para a efetivação do processo curatorial. Vale resșaltar que nem sempre estes processos são cabiveis a todas as instituições ou organizações, sendo necessário adequá-los à̀ tealidade de cada instituiçăo.

O DCC desenvolveu um modelo ${ }^{13}$ de ciclo de vida da curadoria, em que apresenta uma visão geral das etapas necessárias para o processo de curadoria e para a preservação de dados. Conforme destacou-se anteriormente, o modelo pode se ađaptar à necessidade de cada instituição.

Figura 2 - Ciclo de vida da curadoria digital

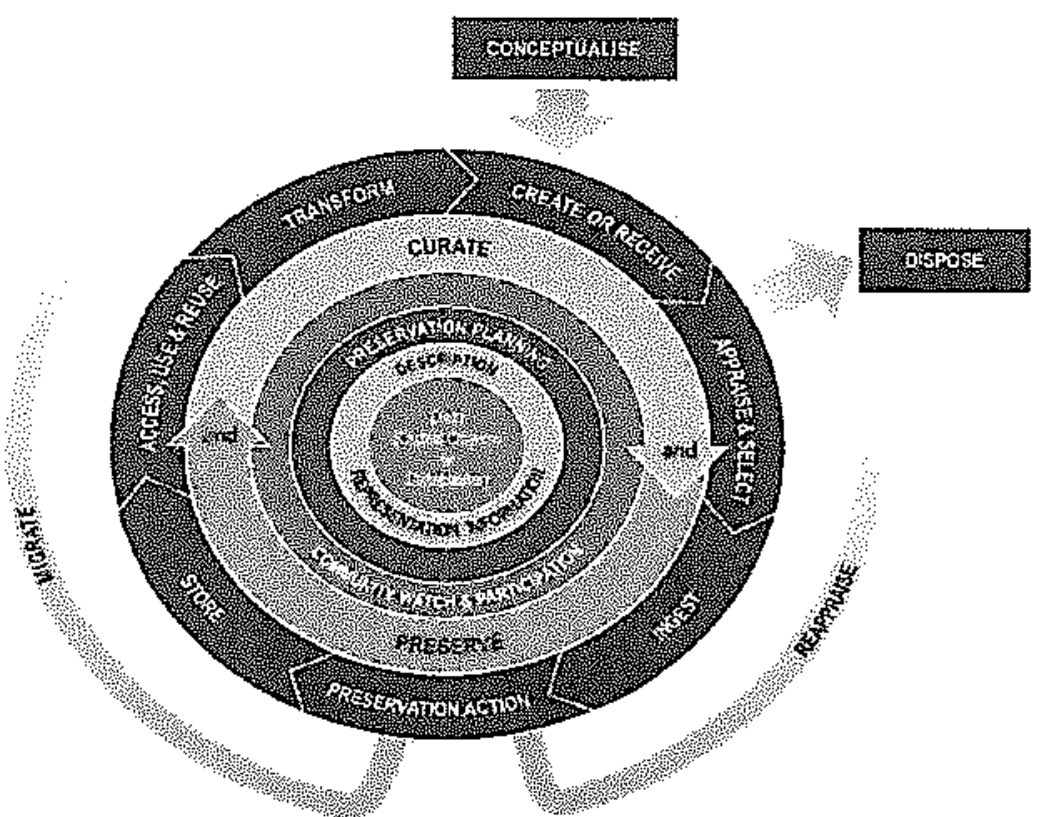

Fonte: Digital Curation Center -.. DCC. Disponivel em: http:/wrw.dcc.ac.uk/resources/curationJifecycle-model Acesso em: 15 maio 2019.

13 Disponivel en: $<$ http://www.dec.ac.uk/resources/curation-lifecycle-model> Acesso em 15 maio 2019. 
Sayão e Sales (2012) discorrem sobre este modelo propösto pelo DCC, apontando que os "elementos-chave são: dado, objetos digitais e base de dados". As ações que devem ser tomadas no decorrer da utilização do modelo também se caracterizam como elemento básico e podem ser classificadas em três tipos: ações para todo o tipo de vida, ações sequenciais e açōes ocasionais.

Ainda de acordo com o DCC, vale ressaltar que as ações sequenciais devem ser realizadas de forma continutada para que o dado permaneça em processo contínuo de curadoria e as ações ocașionais sejam aplicadas de forma eventual, conforme a necessidade.

Entendemoș a partir da análise das açōes propostas pela organização do modelo de ciclo de vida da curadoria digital do DCC (2014), que cada ação, ou o conjunto delas, estầo interligados e em constante atualização e adaptação, de acordo com a instituição em que for utilizada.

Em virtude do que foi mencionado, pretende-se utilizar algumas etapas do ciclo de curadoria digital para aplicação na coleção de teses e disserțaçọes da Biblioteca do Instituto Militar de Engenharia, que é o objeto de estudo desta pesquísa.

A observação dos impactos de açẩo e reação entre os estágios, dinamizando a delegação de responsabilidades dentro de uma instituição e deixando em aberto ações que possam ainda ser acrescidas a este modelo, que não configura um padrão fechado, tendo em vista as conjunturas específicas de cada equipamento, cultural ou não, que decida adotá-lo.

Analisando o ciclo proposto pelo DCC, verifica-se que os objetivos específicos da curadoria digital estão na garantia de algumas características essenciais para a manutenção da relevância e da preservação dos objetos digitais, tais como:

a) a facilidade de acesso ao objeto, tanto à composição quanto à apresentação e conteúto;

b) a autenticidade das informações que o objeto digital pretende transmitịr;

c) a autenticidade, gárantindo também que o objeto não teve alteraçăo indevida ou foi corrompido ao longo do seu ciclo de vida e

d) a confrabilidade, a fim de manter o grau de veracidade da informação contida do objeto em relação ao original.

Com relação ao Brasily a prática da curadoria digital possui um longo caminho a percorrer. As discussões sobre a curadoria digital e sua ligação com a biblioteconomia, a capacidade para o reuso dos objetos digitais já estão presentes em eventos com esta temática $e$ relacionam a cultura e a tecnologia em eventos voltados para as humanidades digitais. 


\section{A BIBLIOTECA DO INSTITUTO MLITAR DE ENGENHARLA E SEU ACERVO}

Como forma de caracterizar o acervo desta pesquisa, identifica-se que a biblioteca do Instituto Militar de Engenharia é uma biblioteca central especializada em engentiaria. Tem como missão "atender as đemandas informacionais da comunidade acadêmica e do públicọ en

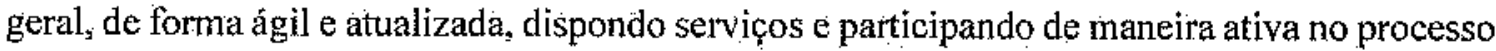
de ensino, pesquisa e extensão". ${ }^{14}$ Sobre bibliotecas especializadas, Ashworth (1967, p. 632 apud SALASÁRIO 2000, p. 106) diz que:

a biblioteca especializada è uma biblioteca quase excitusivamente dedicada a publicaçōes sobre um assunto ou sobre um grupo de assuntos em particular. Inclui tambẹm coleqões de uma espécie particular de dọcumentos.

A Biblioteca General Armando Dubois foi criada com a fusão da Escola Técnica do Exército e do Instituto Militar de Tecnologia, em 04 de novembro de 1959, que deu origem ao Instituto Militar de Engenharia, estando localizada na Urca, Rio de Janeiro. Ronzani, Palazzo e Varandas $(1999$, p. 14) salientam em seu artigo que, em 1969, "a biblioteca contava com 9.186 livros especializados em engenharia e 218 títulos de periódicos".

Acrescenta-se que o acervo existente na biblioteca é composto por obras de referencia (dicionários, anuários, enciclopédias, manuais e guias), acervo bibliográfico de livros, teses e dissertaçốes dos programas de pós-graduação do Instituto, trabalhos de final de curso dos cursos de graduação em engenharia e periódicos.

A biblioteca recebe a produção científica acadêmica do IME em formato impresso e eletrônico. Sobre a guarda da produção cientifica, a biblioteca possui o acervo desde o ano de 1971, em que foi defendida a primeira dissertação referente ao curso de Qụimica, até os dias atuais.

De acordo com os dados consolidados até o primeiro semestre de 2018 , coletados no softivare de bibliotecas PERGAMUM ${ }^{15}$, é possível annalisar a constituição do acervo da biblioteca do IME no quadro abaixo.

14 Disponivel em: http: $/$ wnw.ime.eb.mil.br/pt/biblioteca.html. Acesso em: 08 maio 2019.

150 PERGAMUM - Sistema Integrado de Bibliotecas * é um sistcria informatizado de gerenciamento de dados, directonado aos dịversos tipos de Centros de Informaçầo. Disponível em: hittp://www perganum.pucpr.br/redeperganum/pergamum_intormacoes gerais.php?ind=1. Acesso em: 08 maio 2019. 
Quadro 1-Acervo da biblioteca do $1 \mathrm{ME}$

\begin{tabular}{|c|c|c|}
\hline \multicolumn{3}{|c|}{ Gevantanento bibliografico Geral do acervo } \\
\hline Tipo & Títulos & Exemplares \\
\hline Teses & 1021 & 1028 \\
\hline $\begin{array}{l}\text { Trabalhos de Final de } \\
\text { Curso }\end{array}$ & 542 & 622 \\
\hline Livros & 13.1 .17 & 15.446 \\
\hline Periódicos & 386 & 12.272 \\
\hline Dissertações & 1.705 & 1.716 \\
\hline Total & 16.771 & 31.084 \\
\hline
\end{tabular}

Fonte: soffware PERGAMUM

Analisando o quadro acima, identifica-se que o acervo não possui obras taras e é em sua totalidade composto por monografias. Na biblioteconomia, o termo monografia se refere a livros, folhetos, guias, manuais, relatórios técnicos, obras de referência, normas técnicas, estudos de casos.

O acervo da biblioteca do IME mostra-se importante para o corpo docente e discente do IME, assim como para a comunidade da área de engenharia como um todo. Outrossim, o que se espera é que a preservação da produção cientificica dos docentes e discentes do IME possa refletir na đivulgação dos envolvidos, tanto no Brasil quanto no exterior.

Ainda șobre a produção científica, Witter $(1997, \mathrm{p}, 8)$ define produção científica como

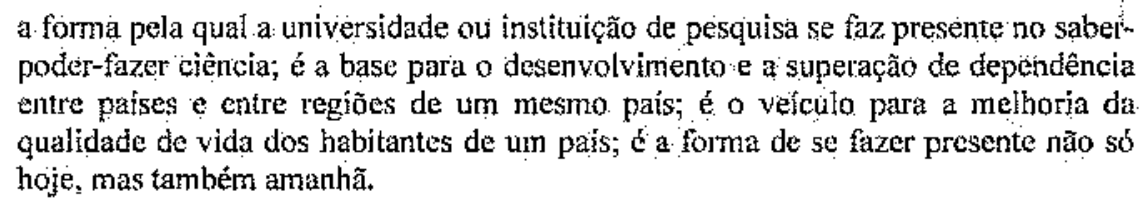

Atender as demandas da sociedade é un dos papéis das universidades por meio de pesquisas, que possuem como resultado a produção científica acadêmica. Sobre o tema Weitzel $(2006$, p. 52) destaca que 
a: produçăo cientifica pode ser entendida como um recurso imprescindível para promover o desenvolvimento da ciência. Sua origem remonta à constituição o consolidação de tọdo um sistema de comuniççăa cientiffca no murudo c sua história está vinculacla à histớria da própria ciêncía, de forma que sua estrutura foi acompanhada pela especialízação dọs sạberes e pela autonomização do campo científico ao longo dos últimos quatro séculos.

Hoje o IME possui uma diverșidade de assuntos e temas registrados em sua produção científica e este fato se deve à quantidade de pesquisadores que fazem parte do instituto, que totaliza 96 docentes. Dentre estes, alguns são civị e a maioria é militar.

O corpo docente da pós-graduação do instituto encontra-se dividido nas seguintes seçốes de ensino:

a) Engenharia de Transportes;

b) Engenharia Elétrica;

c) Ciência dos materiais;

d) Química;

e) Engenharia Cartográfica;

f) Engenharia Nuclear;

g) Sistemas e Computação;

h) Engenharia Mecânica e

i). Engenharia de Defesa:

Diante das seções de ensino citadas, identifica-se que as linhas de pesquisa e desenvolvimento com as quais os docentes ațuam, possuem uma diversidade de áreas e atendem a diversas demandas da sociedade, de forma a abranger sobre construção de estradas, assim como os inpactos da energia nuclear no meio ambiente. São listados abaixo alguns temas, que foram identificados por meio de uma consulta ao sítio do IME:

- Nanopartículas

- Compósitos Geopoliméricos

- Comportamento balistico

- Hidroxiapatita

- Blindagem balística

- Corrosão

- Doença de Alzheimer

- Catalisadores 
Com relação à frẹuência de usuários na bibliọteca, identificou-se um aumento na busca de informaçốes para utilização das ferramentas disponibilizadas em formato digital. Quanto ao acervo em formato impresso, verificou-se que houve uma queda no número de consultas, conforme o Gráfico 1.

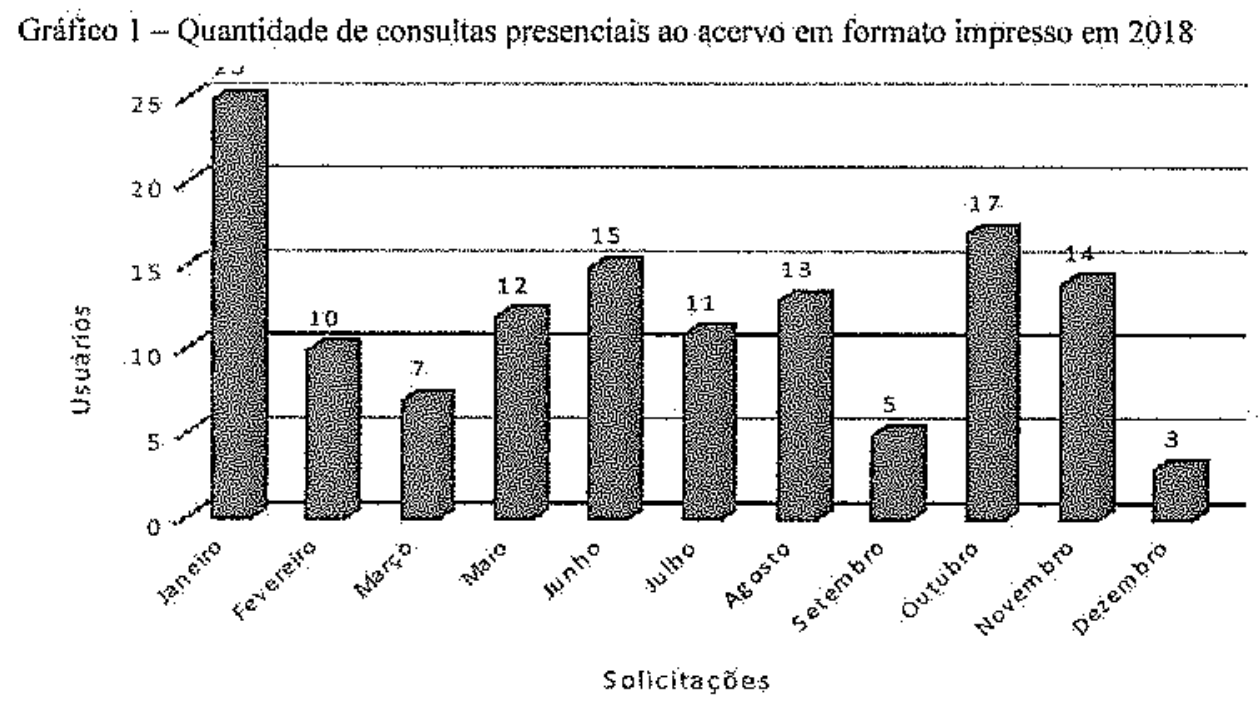

Com base nos dados dispostoș no gráfico acima, identificou-se que, no mês de janeiro de 2018 houve o maior número de consultas ao acervo impresso. A este fato, cabe destacar que janeiro é $O$ mềs que antecede a apresentação e matrícula dos alunos no programa de pósgraduaçăo do instituto, que acontece em fevereiro. Ao serem atendidos na biblioteca, os usuáriọs buscavam consultar os temas ali contidos e localizar material para início de uma proposta de mestrado ou doutorado. Observou-se também que a quantidade de consultas oscilou đurante o ano, com uma queda no mês de dezembro do mesmo ano, que se caracteriza como um periodo de recesso do corpo docente e discente do IME.

Sobre o objeto de estudo desta pesquísa, cabe ressaltar que a coleção de teses e dissertaçôes do IME está, em sua maior parte, disponivel apenạ em formato impresso. Estudos indicam que, no decorrer dos anos, parte da memória acadêmica e científica acabe se perdendo devido à ausência de trạtamento, organização e preservação. Nesta perspectiva,

um dos grandes problemas enfrentados pelas bibliotecas atualimente é o fato de que suas coleçôes estầ num crescerdo de deterioração. $O$ acervo bibliográfico sob a guarda de nossas bibliotecas é matéria orgânica e, como tal, tem um tempo de vida. 
Diante desse fato, uma outra questão se apresenta, tão clamorosa quanto a primeira: o binônio preservaçăo - acesso (I.XNO; HANNESCH; AZEVEDO, 2006. p. 2).

No entanto, existem medidas visando à minimização dọs riscos de perda e deterioração aos itens em formato impresso. Tais medidas devem estar inclusas em um plano de preservação de acervos de bibliotecas universitárias, de forma que compreenda também os documentos digitais.

\section{CONSIDERAÇÕES FINAIS}

O objetivo desta pesquisa foi o de abordar sobre as vantagens da utilização da curadoria digital no acervo de teses e dissertaçôes do IME. A partir daí, verificou-se que há muitos procedimentos a serem realizados e um longo caminho a ser percorrido para a conclusão das etapas da curadoria digital citadas nesta pesquisa, Acredita-se que as ações desenvolvidas no ciclo da curadoria digital possam contribuir para a preservação e a difusão de um acervo importante para a história da engenharia no Brasil.

A curadoria digital possibilita urna nova forma de preservação dos objetos digitais. No caso da biblioteca do $\mathrm{IME}_{\xi}$ as atividades ainda estão sendo desenyolvidas e o ciclo de curradoria digital poderá contribuir de forma efetiva para a preservação e difusão da importante coleção de teses e dissertaçôes dọ instituto. Resgatar a memória acadêmica possibilita o reuso e compartilhamento das informações ali contidas e no caso de uma instituiçẫo pautada em ciência e tecnologia, pode economizar anos de estudos e resultados mais rápidos em pesquissas.

A digitalização e consequentemente a disponibilização deste acervo permitirá que a informação chegue a pesquisadores de todo o mundo, além de prevenị contra o desgaste e salvaguardar o acervo impresso. Com a migração do formato fisico para o digital identifica-se que a biblioteca do IME tem uma preocupação no que diz respeito à preservação do conhecimento ali produzido.

Identificou-se ainda que o uso das redes sociais deve ser implementado na biblioteca do IME, visto que possibilita alcançar um público diverso e divulgar serviços que desenvolve. Além disto, a rede social é um canal que atinge principalmente o público que não frequenta o instituto.

Por se tratar de uma biblioteca universitária, a biblioteca do IME, poderá então, auxiliar neste sentido, criando formas de melhoria da competência em informação de seus usuários, a fim de que eles se harmonizem a esta nova realidade e possam ter acesso à informação de que 
precisam para transformá-las em conhecimento, fazendo com que haja a evolução científica tão. necessária para a sociedade brasileira atulal.

\section{REFERÊNCIAS}

ABBOT, Daisy. What is digital curation? Edinburgh, UK: Digital Curation Centre, 2008. Disponível em: http://www.era.lib.ed.ac.uk/bitstream/1842/3362/3/Abbott\%20What $\% 20$ is $\% 20 \mathrm{~d}$ igitl\%20curation_\%20 \%20Digital\%20Curation\%20Centre.doc. Acesso em: 02 fev. 2019.

BEAGRIE, Neil. Digital Curation for Science, Digital Libraries, and Individuals. The International Journal of Digital Curation, Edinburgh, v. 1, n. 1, p.3-16, out. 2006. Disponivel em: http://www.ijdc.net/index.php/ijdc/article/view/6/2. Acesso em: 04 abr. 2019.

BELCHIOR, Vaneșa Ferreira. A curadoria digital como meio de preservação e difusão da coleção de teses e dissertações do Instituto Militar de Engenharia - IME. 2019. Dissertação (Mestrado em Preservação de Acervos de Ciência e Tecnologia) - Museu de Astronomia, Rio de Janeiro, 2019.

DALLAS, C. Digital curation beyond the "wild frontier": a pragmatic approach. Archival Science, v. 16, p. $421-457$, set. 2016.

DESVALLEEES, André; MAIRESSE, Françớs (ed.). Conceitos-chave de Museologia. São Paulo: Comitê Brasileiro do Conselho Internacional de Museus: Pinacoteca do Estado de São Paulo: Secretaria de Estado da Cultura, 2013. Disponível em: http://icom.museum/fileadmin/user_upload/pdf/Key_Concepts_of _Museology/ConceitosChavedeMuseologia pt.pdf $>$ Acesso em: 03 mar. 2019.

DIGITAL CURATION CENTRE. The DCC curation lifecycle model. 2008. Disponível em: http://www.dce.ac.uk/resources/curation-lifecycle-model, Acesso em: 08 abr, 2019.

DUTRA, Moisés Lima; MACEDO, Dougias Dyllon Jeronimo de. Curadoria digital: proposta de um modelo para curadoria digital em ambientes big data baseado numa abordagem semiautomática para a seleçã̃o de objetos digitais. Informação \& Informação, [S.l.], v. 21, n. 2. p. 143-169, dez. 2016. Disponivel em: http:/www.uel.br/revistas/uel/index.php/informacao/article/view/27176/20125. Acesso em: 07 jul. 2019.

FERREIRA, S. M. S. P. Repositórios versus revistas científicas: convergências e convivências. In: FERREIRA, S. M. S. P.; TARGINO, M. G. (org.). Mais sobre revistas cientificas: em foco a gestão. São Paulo: Ed. Senac, 2008.

HOLLÓS, Adriana C. Entre o passado e o futuro: limites e possibilidades da preservação documental no Arquivo Nacional do Brasil. 2006. Dissertação (Mestrado em Memória Social) - Universidade Federal do Rio de Janeiro, Rio de Janeiro, 2006. Disponivel em: http:// 
http:/eprints.rclis.org/17025/1/dissertação\%20Adriana\%20Hollós.pdf. Acesso em: 23 fev. 2019.

HOLLÓS, Adriaria C. O futuro da memória digital na Administração Pública Federal Brasileira. 2014. Tese (Doutorado em Ciência da Informação) - Instituto Brașileiro de Informação em Ciência e Tecnologia, Universidade Federal do Rió de Janeiro, Escola de Comunicação, Rio de Janieiro, 2014. Disponivel em: http://eprints.rclis.org/28359/1/Tese $\% 20 \% 20$ Adriana $\% 20 \mathrm{Cox} \% 20$ Hollos.pdf. Acesso em: 23 fev 2019.

LINO, Lucia Alves da Silva; HANNESCH, Ozana; AZEVEDO, Fabiano Cataldo de. 2006. Política đe Preservação no ầmbito do gerenciamento de Coleções Especiais: um estudo de caso no Museu de Astronomia e Ciências Afins, 2006. In: ENCONTRO NACIONAL DE ACERVO RARO, 7., 2006, Rio de Janeiro. Encontro[...] Rio de Janeiro: PLANOR, 2006.

LYNCH, Clifford A. Institutional Repositories; Essential Infraestructure for Scholarship inthe Digital Age. ARL Bimonthly Report 26. Disponível em: https:/wwwarl.org/resources/pubs/br/br226/br226ir.shtml. Acesso em: 23 fev. 2019.

MARCONDES, Carlos Henrique; SAYÃO, Luis Fernando. Software livres para repositórios institucionais: alguns subsídios para a seleção. In: SAYÃO, Luis et al. Implantação e gestāo de repositórios institucionaiș: políticas, memória, livre acesso e preservação. Salvador: EdUFBA, 2009.2 p. 23-54. Disponivel https:/repositorio.ufba.br/ri/bitstream/ufba/473/3/implantacao_repositorio_web.pdf. Acesso em: 05 maio 2019.

SALASÁRIO, Maria Guilhermina Cunha. Biblioteca especializada e informação: da teoria conceitual à prática na biblioteca do labboratório de Mecânica Precisão-LMP/UFSC. Revista ACB, $[S . l], \quad$ v. $5, \quad$ n. 5, p. 104-119, ago. 2005. Disponível em: https://revista.acbsc.org.br/racb/article/view/35 I/415. Acesso em: 10 dez. 2019.

SONDERGAARD, T; F; ANDERSEN, J; HJORLAND, $B$. Documents and the communication of scientific and scholarly information: Revising and updating the UNISIST model. Journal of Documentation, y. 59, n. 3, p. 278-320, 2003.

RONZANI, E. R.; PALLAZO, M.; VARANDAS, G. Histórico da Pós-graduação no IME. Revista Militar de Ciência e Tecnologia, 1999.

RUSBRJDGE, $\mathrm{C}$. et al. The digital curation centre: a vision for digital curation. $l n$ : IEEE INTERNATIONAL SYMPOSIUM ON MASS STORAGE SYSTEMS AND TECHNOLOGY, 2005. Disponíyel em: https://ieexplore.ieee.org/document/1612461/?reload=true. Acesso em: 25 jun. 2019.

SAYÃO, Luís Fernando. Uma outra face dos metadados: informações para a gestão da preservação digital. Encontros Bibli: Revista Eletrônica de Biblioteconomia e Ciência da Informação, Florianópolis, v. 15, n. 30, p. 1-3i, 2010. Disponível em: https://periodicos.ufsc.br/index.php/eb/article/view/12528. Acesso em: 10 jul. 2019. 
SAYÃO, Luís Fernando. Digitalização de acervos culturais: reuso, curadoria e preservação. In: SEMINARIO DE SERVIÇOS DE INFORMAÇÃO EM MUSEUS: informação digital como patrimônio cultural, 4.; 2016, São Paulo. Anais [...] São Paulọ: 2016.

YAKEL, E, Digital curation. OCLC Systems \& Services: International digital library perspectives, vol. 23, n. 4, p.335-340, abr. 2007.

WEITZEL, Simone da Rocha. O papel dos repositórios institucionais e temáticos na estrutura da produção científica. Em Questão, Porto Alegre, v. 12, n. 1, p. 51-71, jan /jun, 2006.

WITTER, Geraldina Porto: Produção científica. Campinas, SP: Editora Átomo, 1997. 